\title{
Service Quality Gaps \& Six Sigma
}

\author{
Ali Dehghan \\ Dept. of Engineering Management, Eastern Michigan University \\ 2951 International Dr \#2020C, USA \\ Tel: 1-734-277-4914_E-mail: ali.dehghan3@gmail.com
}

\author{
Arash Shahin \\ Department of Management, University of Isfahan \\ Hezar Jarib St., Isfahan 81746-73441, Iran \\ Tel: 98-311-793-2040_E-mail: arashshahin@hotmail.com
}

\author{
Bahman Zenouzi \\ CCG CO, Customer Centric Group \\ No 27, Zohre, Park Way, Chamran,Tehran, Iran \\ Tel: 98-21-2266-5086Ｅ-mail: Chief@ccgccc.at
}

Received: August 17, 2011 Accepted: August 29, 2011 Published: January 1, 2012

doi:10.5296/jmr.v4i1.887ＵRL: http://dx.doi.org/10.5296/jmr.v4i1.887

\begin{abstract}
Nowadays almost all organizations are realizing the significance of customer centered philosophies. One of the key challenges they are facing is how to manage service quality, which holds a great importance to customer satisfaction. This paper has attempted to investigate the gap between customers, service providers and managers in terms of service quality dimensions. For this purpose, gaps 1 and 6 of the SERVQUAL model have been studied, as well as two new gaps, proposed for comparing customer perceptions and employee perceptions of customer perceptions. Service quality dimensions have been analyzed, considering a case study in Customer Centric Group Company (CCG Co). The empirical data has been gathered through in dept interviews. The role of Six Sigma has also been investigated in this paper and it has been highlighted that how such advanced quality engineering approach could tighten service quality gaps. The results imply that among
\end{abstract}




\section{Macrothink

studied service quality dimensions, assurance has the highest gap and tangible has the lowest. Additionally, it has been found that Six Sigma might not have a direct impact on service quality gaps, rather it affect them indirectly through customer satisfaction, i.e. customer perceptions.

Key words: Service quality gaps, SERVQUAL, Customer, Expectations, Perceptions, Six Sigma 


\section{Introduction}

Managers in the service sector are under increasing pressure to demonstrate that their services are customer-focused and that continuous performance improvement is being delivered. Given the financial and resource constraints under which service organizations must manage it is essential that customer expectations are properly understood and measured and that, from the customers' perspective, any gaps in service quality are identified. This information then assists a manager in identifying cost-effective ways of closing service quality gaps and of prioritizing which gaps to focus on - a critical decision given scarce resources.

While there have been efforts to study service quality, there has been no general agreement on the measurement of the concept. The majority of the work to date has attempted to use the SERVQUAL (Parasuraman et al. , 1985; 1988) methodology in an effort to measure service quality (e.g. Brooks et al., 1999; Chaston, 1994; Edvardsson et al., 1997; Lings and Brooks, 1998; Reynoso and Moore, 1995; Young and Varble, 1997; Sahney et al. , 2004). Taking in to account these developments, it is evident that service researchers need to pay more attention to consumer evaluations of technology-based services (Parasuraman and Grewal, 2000).

Customer Centric Group (CCG) Co has partners in supplying the whole range of HV substation products and has organized engineering and expert groups in a way to be able to provide full range of product generations, $T \& D$ and utilization skills and all related services. This article examines the service quality in a company that is experiencing changes in its competitive environment because of restructuring and deregulation in the industry. It also demonstrates the SERVQUAL model of service quality gaps and identifies specific improvements that must be made to the design and delivery of services to meet and exceed customer perceptions. The received wisdom within the electrical substation industry is that the business is totally driven by price and availability.

CCG Co is the leading electrical substation (PASS) contractor in Iran with additional operations. Its primary customers include other contractors companies in the country. CCG $\mathrm{CO}$ customers believe that the price of offered services is too high and usually the company considers only its immediate margin, not customer's benefits. It seems that the speed of service delivery is not satisfactory, conversely CCG Co believes that customers expectations are not logical, so on both sides, the company and customers become dissatisfied.

It is important to note that the CCG Co provides customers with high quality services to survive in this highly competitive electrical industry business. Regarding this importance, CCG Co, first needs to understand the attributes that customers use to judge about service quality and monitor and enhance the service performance. There are numerous studies that identifies key service quality dimensions in other businesses, but relatively little literature is available on service quality attributes in the electrical industry, particularly in Iran and analysis of service quality gaps (Jun and Cai, 2001).

Another aim of this study is to explore the role of Six Sigma in closing service quality gaps. Another aim of this paper is to point out how management of service improvement can become more logical and integrated with respect to the prioritized service quality dimensions and their affections on increasing/decreasing service quality gaps. In the following, after a 
brief introduction to customer satisfaction and service quality, the case of CCG Co, is studied. Next, Six Sigma and its role in customer satisfaction and closing gaps are addressed and major conclusions are derived.

\section{Customer satisfaction and service quality}

Customer satisfaction is a critical issue in the success of any business system, traditional or online (Ho and Wu, 1999). Satisfaction occurs when someone successfully achieves his/her goals (Johnson, Aragon, Shaik, \& Palma-Rivas, 2000). Customer satisfaction can be obtained when the actual performance exceeds the expectations of those being served (Dehghan \& Shahin, 2011). If product performance is worse than expected performance, negative disconfirmation occurs and leads to dissatisfaction (Chen-Yu, Williams \& Kincade, 2009). In a turbulent commerce environment, in order to sustain the growth and market share, companies need to understand how to satisfy customers, since customer satisfaction is critical for establishing long-term client relationships (Patterson et al. 1997). It is evidenced by the fact that over the last five years, customer satisfaction surveys have become a common important issue in many financial institutions. Thus, a fundamental understanding of factors impacting customer satisfaction is of great importance to commerce. Furthermore, the need for research on customer satisfaction has been accentuated by the increasing demand for the long-term profitability of dotcom companies and traditional companies (Pather et al., 2002). Literature shows that relationship between satisfaction and service quality is the key to measure user satisfaction (Pitt et. al., 1995).

Service quality is a concept that has aroused considerable interest and debate in the literature, because of the difficulties in both its definition and measurement with no overall consensus emerging on either (Wisniewski, 2001). There are a number of different definitions for service quality. One which is common defines service quality as the extent to which a service meets customers' needs or expectations (Lewis and Mitchell, 1990; Dotchin and Oakland, 1994a; Asubonteng et al., 1996; Wisniewski and Donnelly, 1996). According to the service quality gaps model (Appendix 1), service quality can be defined as the difference between customer expectations of service and perceived service (as a basis for SERVQUAL). If expectations are greater than performance, then perceived quality is less than satisfactory and hence customer dissatisfaction occurs (Parasuraman et al., 1985; Lewis and Mitchell, 1990). Some important definitions of service quality are as follows:

- Parasuraman et al., (1985; 1988): "Service quality is determined by the differences between customer's expectations of services provider's performance and their evaluation of the services they received".

- Asubonteng et al. (1996): "Service quality can be defined as "the difference between customers” expectations for service performance prior to the service encounter and their perceptions of the service received".

There always exists an important question: why should service quality be measured? Measurement allows for comparison before and after changes, for the location of quality related problems and for the establishment of clear standards for service delivery. Edvardsen et al. (1994) state that in their experience, the starting point in developing quality in services 
is analysis and measurement. SERVQUAL as the most often used approach for measuring service quality is used to compare customers' expectations and their perceptions of the actual service delivered (Gronroos, 1982; Lewis and Booms, 1983; Parasuraman et al., 1985), which is referred to as gap 5 in the model of service quality gaps (Appendix 1).

Just over a decade ago, Parasuraman et al. (1985) initiated a research stream that many consider to be the most comprehensive investigation into service quality. Briefly, Parasuraman et al. (1985) proposed service quality to be a function of pre-purchase customer expectations, perceived process quality, and perceived output quality. They defined service quality as the gap between customers' expectations of service and their perceptions of the service experience, ultimately deriving the now-standard SERVQUAL multiple-item survey instrument (Parasuraman et al., 1988). The SERVQUAL instrument has been the predominant method used to measure consumers' perceptions of service quality. It has five generic quality dimensions as follows (van Iwaarden et al. , 2003):

- Tangibles: Physical facilities, equipment and appearance of personnel.

- Reliability: Ability to perform the promised service dependably and accurately.

- Responsiveness: Willingness to help customers and provide prompt service.

- Assurance: Knowledge and courtesy of employees and their ability to inspire trust and confidence (including competence, courtesy, credibility and security).

- Empathy: Caring and individualized attention that the firm provides to its customers (including access, communication, understanding the customer).

In this study, the service quality model and the methodology developed by Parasuraman et al. (1988), Zethaml et al. (2000; 2002) and Shahin (2004) provide main pillars of investigation.

\section{Methodology}

Considering the model of service quality gaps, gaps 1 and 6 are targeted in this research. Also, two new gaps are suggested and analyzed, by which, customer perceptions could be compared with employee and managers perceptions of customer perceptions (new gaps 1 and 2 in Figure 1). The authors also consider Six Sigma approach. Breyfogle III et al. (2001) expressed that the major components to consider during Six Sigma implementation are "metrics" and "strategy". The application of Six Sigma strategy seems to be clear. Once the metrics are measured and prioritized, then the associated service processes will be improved through the implementation of a continuous Six Sigma strategy (e.g. DMAIC methodology). The important point is to develop metrics for service quality gaps in a way to be able to be converted into ppm and Sigma levels. The authors found this hard to apply Six Sigma metrics directly in gaps analysis. Rather, they suggest that the study should be conducted in two stages; first measuring the gaps and then after targeting service quality dimensions, consider customer perceptions as indicators of customer satisfaction and metrics for Sigma analysis. The new approach is illustrated in Figure 2. It is important to note that the integration of Six Sigma and the model of service quality gaps is the only possible for customer perceptions, not expectations, since perceptions are actually the true indicators of customer satisfaction, not expectations. From this point of view, Six Sigma strategy could be applied for closing all gaps, but Six Sigma metrics could be defined for those gaps, which are based on perception 
or performance.

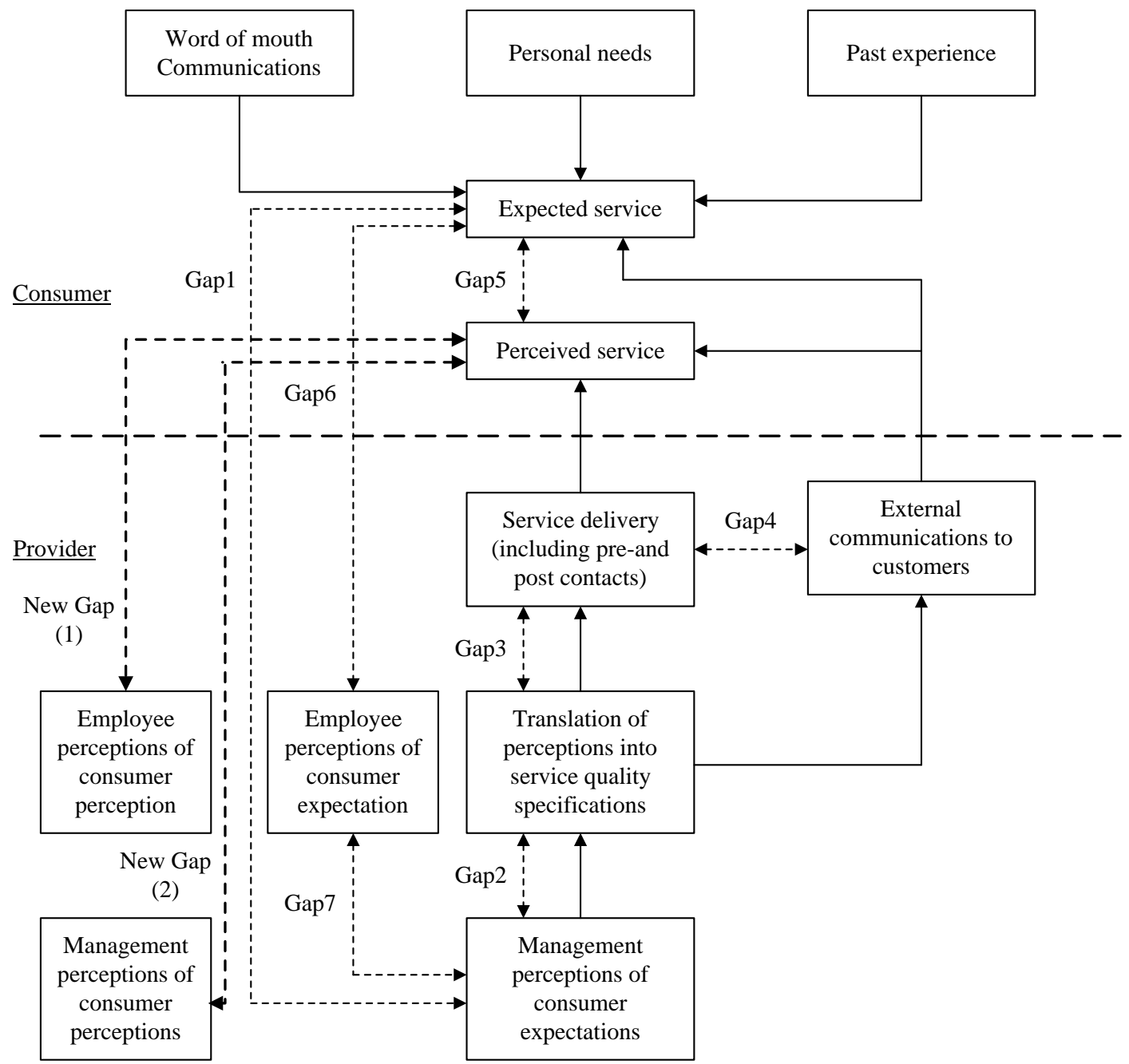

Figure 1. New methodology: Model of service quality gaps with two new gaps 


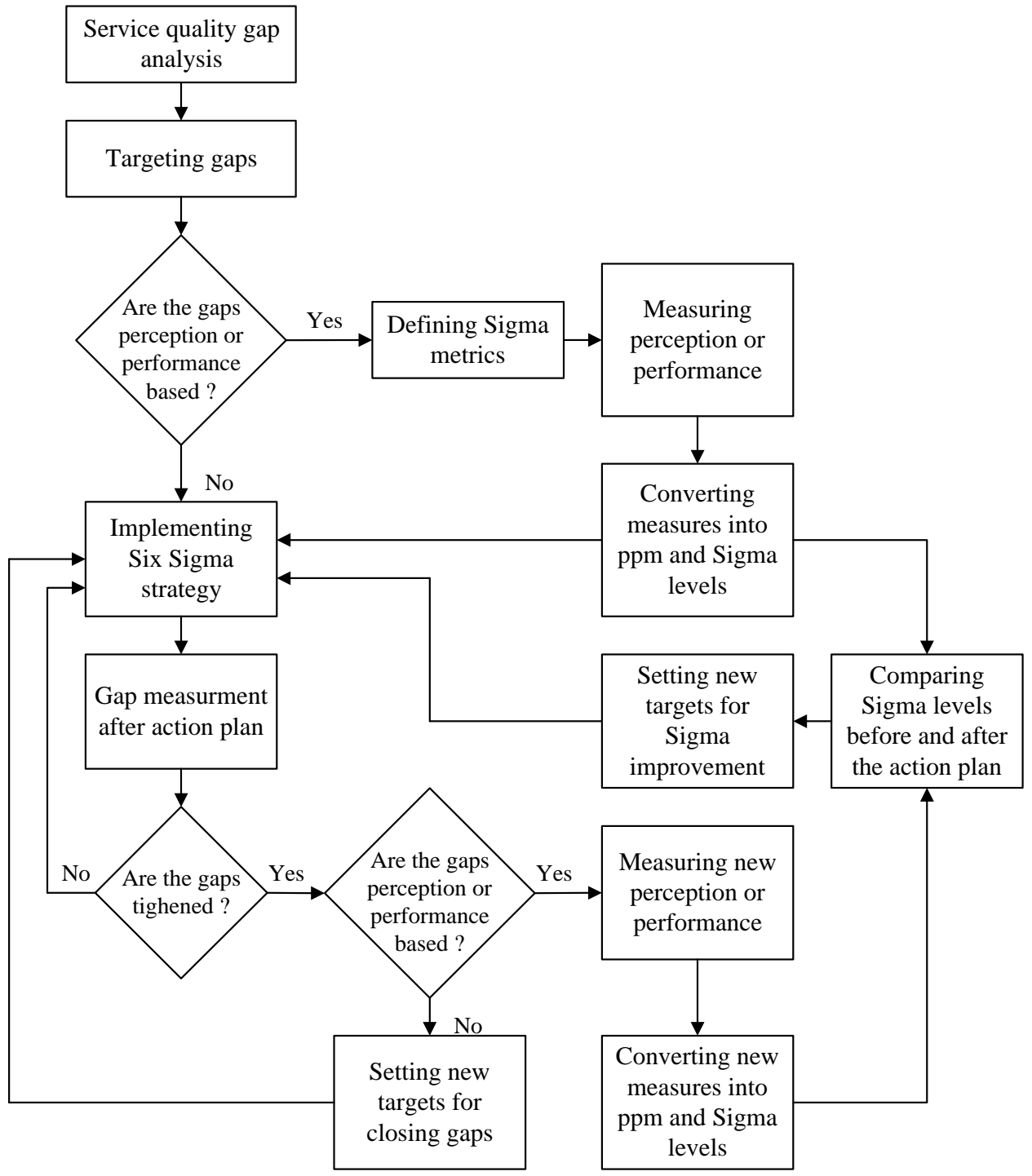

Figure 2. New methodology: Integration of Six Sigma approach and service quality gaps analysis

\section{Case Study}

Responsiveness, Assurance and Empathy were conducted with CCG Co president and a number of its customers. These interviews provided the necessary background information about the service system. In the next step, gap 5 was measured. A list of the current quality characteristics of CCG Co was made and measured in terms of two new gaps and gaps 1 and 6, based on interviews with participation of two customers and the CCG Co.'s president, managers and service providers. All the interviews were conducted considering five dimensions of service quality. The results are summarized in Figure 3. 


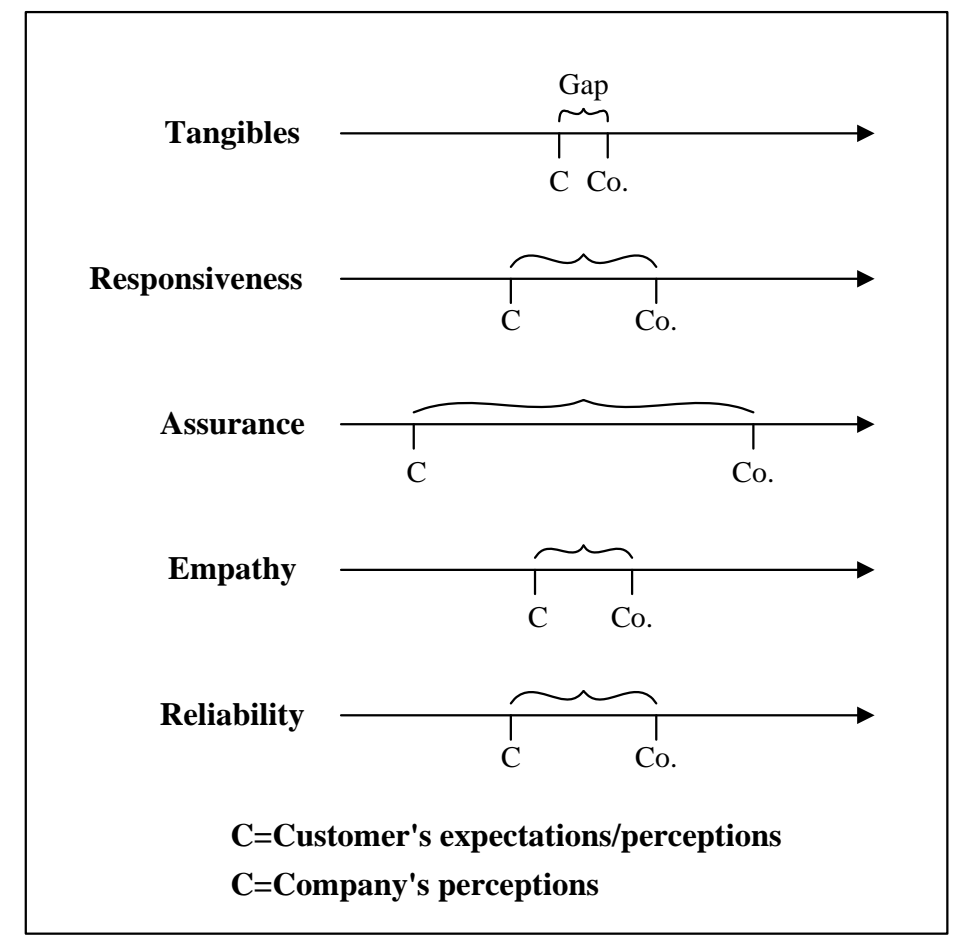

Figure 3. Service quality gap analysis in CCG Co.

\section{Discussion and Conclusions}

In this study, two new methodologies were proposed. First, the model of service quality gaps was discussed. Respectively, two new gaps were added to measure the differences between managers' and service providers' perceptions of customers' perceptions and customer perceptions. This was adopted in CCG Co. Also, the authors proposed a new methodology for integration of Six Sigma and service quality gaps analysis. Although the second proposed methodology was not conducted in the case study, it seems to provide great opportunities to the researchers who are interested in the development of the applications of advanced quality engineering approaches for service industry.

With respect to the case study, the findings imply that the Assurance dimension has the highest gap value. Considering the literature review, the assurance dimension has four sub-categories, including competent, courtesy, and credibility. Therefore, it is suggested to CCG Co to hire more expert employees to do more projects in order to get better experiences; also those employees should be able to convince the customers and totally make the CCG Co more competent in order to prevail its competitors, otherwise customers will switch to other companies.

Findings reveal that according to the brand name of the service provider, i.e. Customer Centric Group Co, customers can expect whatever they desire, logically or illogically; therefore, a big gap occurs between the service provider's perception and customer's expectation in the case of responsiveness. The findings also indicate that quick response is one of the key drivers of customer satisfaction/ dissatisfaction. More importantly, the findings indicate that some customers expect and need personalized services from the CCG Co. 
Personalized services could establish and extend good relationship with customers and lead to customer trust and loyalty. In the case of reliability, the findings highlight the fact that the CCG Co should try to speed up installation time by using more expert engineers and technicians. This in turn leads to more customer trust and satisfaction and creates a confidential atmosphere. Since the products can be delivered faster, customers could be asked to pay higher prices for earlier delivery.

Although almost all references in the literature review emphasize on five classic dimensions of service quality, one of the important factors that is not found in the theory is "price". This study implies that reasonable price and cost of the services are important factors in terms of customer satisfaction. All the customers believe that the services are not cost effective and too expensive, therefore CCG Co must decrease the costs and prices in order to be survived in such a competitive and complex market, otherwise it will lose its market share thoroughly. Three more dimensions which seem not to be addressed in the literature are found to be important in this study and are suggested to be mentioned as service quality dimensions. They include "technology update", "logistical or technical equipment" and "personalization or customization”, that should be mentioned in quality improvement program of CCG Co. Consequently, nine service quality dimensions are found important in this study as tangibles, responsiveness, reliability, assurance, empathy, pricing, technology update, logistical or technical equipment, and personalization and customization. The first five dimensions were investigated in this paper. The rest should also be researched in terms of gap analysis and Six Sigma methodology. All the nine dimensions are significant factors to analyze services of CCG Co, but in the case of research limitations at CCG Co, price and the first five key dimensions are emphasized to be seriously studied and taken into a consideration.

\section{References}

Anderson, E.W. \& Sullivan, M.W. (1993). The antecedents and consequences of customer satisfaction for firms, Marketing Science, 12(2), Spring. http://dx.doi.org/10.1287/mksc.12.2.125

Asubonteng, P. Mccleary, K.J. \& Swan, J.E. (1996). SERVQUAL revisited: a critical review of service quality, The Journal of Services Marketing, 10(6), pp. 62-81. http://dx.doi.org/10.1108/08876049610148602

Awad, E.M. (2000). The Structure of E-Commerce in the Banking Industry: An Empirical Investigation, USA: S1GCPR 2000 Evanston Illinois.

Bahia, K. \& Nantel, J. (2000). Areliableand valid measurement scale for the perceived service quality of banks, International Journal of Bank Marketing, 18(2), pp.84-91.

Bellini, N. (2002). Perceived quality in the delivery of Business support services: a conceptual framework with practical implication, European seminar on support services for micro small and sole proprietor's businesses.

Bitner, M.J., Booms, B.H. \& Tetreault, M.S. (1990). The Service Encounter: Diagnosing Favorable and Unfavorable Incidents, Journal of Marketing, 54, January. 
http://dx.doi.org/10.2307/1252174

Boulding, W., Kalra, A., Staelin, R. \& Zeithaml, V.A. (1993). A Dynamic process model of service Quality: from expectations to behavioral intentions. Journal of Marketing Research, 30(1), February, pp. 7-27. http://dx.doi.org/10.2307/3172510

Breyfogle III, F.W., Cupello, J.M. \& Meadows, B. (2001). Managing Six Sigma: A practical guide to understanding, assessing, and implementing the strategy that yields bottom-line success, USA: John Wiley \& Sons, Inc.

Cadotte, E.R., Woodruff, R.B. \& Jenkins, R.L. (1987). Expectations and norms in models of consumer satisfaction. Journal of Marketing Research. 24(3), pp. 305-314. http://dx.doi.org/10.2307/3151641

Caruana, A. \& Malta, M, (2002). Service loyalty-The effects of service quality and the mediating role of customer satisfaction, European Journal of Marketing, 36(7/8), pp.811828.

Churchill, G.A. \& Surprenant, C. (1992). An Investigation into the Determinant of Customer Satisfaction, Journal of Marketing Research, 19, pp. 491-504. http://dx.doi.org/10.2307/3151722

Cooper, D.R. \& Schindler, P.S. (2003). Business Research Methods, 8th edition, McGraw-Hill Companies, Inc.

Creswell, J.W. (2003). Research Design: Qualitative, Quantitative and Mixed Methods Approach, Second edition, Sage Publication, Inc.

Cronin, J.J. \& Taylor, S.A. (1992). Measuring Service Quality: A Re-examination and Extension, Journal of Marketing, 56 (July), pp. 55-68.

Curry, A. (1999). Innovation in public service management, Managing Service Quality, 9(3), pp. 180-190. http://dx.doi.org/10.1108/09604529910267082

Daniel, E. (1999). Provision of electronic banking in the UK and Ireland, International Journal of Bank Marketing, 17(5), pp.211-232. http://dx.doi.org/10.1108/02652329910258934

Dehghan, A. \& Shahin, A. (2011). Customer Loyalty Assessment-A Case Study in MADDIRAN, the Distributor of LG Electronics in Iran. Business Management and Strategy, $2(1)$.

Luk, Sh.T.K. \& Layton, R. (2002). Perception Gaps in customer expectations: Managers versus service providers and customers, The Service Industries Journal, 22(2), April, pp. 109-128. http://dx.doi.org/10.1080/714005073

Parasuraman, A., Berry, L.L. \& Zeithaml, V.A. (1994). Alternative Scales for Measuring Service Quality: A Comparative Assessment Based on Psychometric and Diagnostic Criteria, Journal of Retailing, 70 (3), pp. 201-30.88. http://dx.doi.org/10.1016/0022-4359(94)90032-9 


\section{Macrothink}

Journal of Management Research ISSN 1941-899X 2012, Vol. 4, No. 1: E3

Parasuraman, A., Zeithamal, V.A. \& Berry, L.L., (1988). SERVQUAL: A Multiple-Item Scale for Measuring Consumer Perceptions of Service quality, Journal of retailing, 64(1), spring.

Parasuraman, A., Zeithaml, V.A. \& Berry, L.L. (1985). A conceptual model of service quality and its implications for future research. Journal of Marketing, 49, Fall. http://dx.doi.org/10.2307/1251430

Pitt, L.F., Watson, R.T. \& Kavan, C.B. (1995). Service Quality: A measure of information systems effectiveness. MIS Quarterly, June. http://dx.doi.org/10.2307/249687

Saunders, M., Lewis, P. \& Thornhill, A. (2000). Research Methods for Business Students, Second Edition, UK: Financial Times, Prentice Hall.

Spreng, R.A., Mackenzie, S.B. \& Olshavky, R.W. (1996). A reexamination of the determinants of customer satisfaction. Journal of Marketing, 60(3), pp 15-33, July.

Shahin, A., (2004). SERVQUAL and Model of service quality gaps: A framework for determining and prioritizing critical factors in delivering quality services, 4th international conference on quality management, Docs/0077. 